\title{
Rigidez e subjetividades: uma análise cultural em uma organização policial*
}

\author{
Elias Pereira Lopes Júnior** \\ Thiago Alves Paiva*** \\ Henrique Muzzio**** \\ Francisco José da Costa*****
}

Sumário: 1. Introdução; 2. Referencial teórico; 3. Metodologia; 4. Resultados da pesquisa empírica; 5 . Comentários e considerações finais.

Summary: 1. Introduction; 2. Theoretical framework; 3. Methodology; 4. Results of the empirical research; 5. Comments and conclusions.

Palavras-chave: cultura organizacional; administração pública; polícia civil.

KEY WORDS: organizational culture; public administration; police organization.

Este artigo tem como objetivo analisar a cultura organizacional da Polícia Civil do estado do Ceará, contribuir nas análises dessas entidades a partir da apresentação de evidências ilustrativas das características organizacionais em termos de cultura e melhorar a compreensão das peculiaridades próprias do serviço público, mais especificamente das instituições repressoras ao crime. Foi desenvolvida uma revisão de literatura e um estudo de campo, por método de estudo de caso. O objeto

\footnotetext{
* Artigo recebido em jul. 2009 e aceito em jul. 2010.

** Mestre em administração pela Universidade Estadual do Ceará (Uece). Professor na Faculdade Sete de Setembro. Endereço: rua Escrivão Azevedo, 680, bl. B, ap. 1 — Cidade dos Funcionários — CEP 60822-520, Fortaleza, CE, Brasil. E-mail: eliasjunior08@gmail.com.

*** Bacharel em administração pela Uece. Mestrando do Curso de Mestrado Acadêmico em Administração (Uece). Endereço: av. Santos Dumont, 6911, bl. 1, Delta 604 — CEP 60150-240, Fortaleza, CE, Brasil. E-mail: talvesp@gmail.com.

***** Doutor em administração pela Fundação Getulio Vargas de São Paulo (FGV/SP). Professor e pesquisador na Faculdade Christus. Endereço: rua Rangel Pestana, 950, complemento 18 - Sapiranga — CEP 60834-250, Fortaleza, CE, Brasil. E-mail: hmuzzio@bol.com.br.

$* * * * *$ Doutor em administração pela FGV/SP. Professor do Curso de Administração na Universidade Federal da Integração da Lusofonia Afro-Brasileira (Unilab). Endereço: rua Jorge Dumar, 2001 — Benfica - CEP: 60410-300, Fortaleza, CE, Brasil. E-mail: franzecosta@gmail.com.
} 
de análise foi a Polícia Civil do estado do Ceará e foram realizadas oito entrevistas semiestruturadas, transcritas e analisadas diante dos objetivos da pesquisa. A análise da fala dos respondentes indicou que prevalecem, na instituição analisada, posições fragmentadas, ambíguas e contraditórias, que podem surgir a partir das tensões entre estruturas mentais pré-constituídas (especialmente em relação ao papel da burocracia) e as práticas e processos oriundos da construção social dos atores organizacionais. As passagens dos relatos dos delegados ilustram que, mesmo considerando o nível de padronização exigido em uma organização policial, até mesmo os líderes das organizações de base (delegacias) são divergentes em diversos aspectos da atividade e da cultura organizacional.

\section{Rigidity and subjectivities: a cultural analysis in a police organization}

This study aims to examine the organizational culture in police organizations, contribute in the analysis of these entities from the presentation of showing evidences the characteristics in terms of organizational culture and improve understanding of the own peculiarities of the public service, specifically the repressive institutions against crime. It developed a literature review and field study by case study method. The object of analysis was the Civil Police of Ceará's state and eight semi-structured interviews were conducted, transcribed and analyzed. The analysis of the speech of the respondents indicated that prevail in the analyzed institution, fragmentary, ambiguous and contradictory positions, that may arise from tensions between preformed mental structures (especially in relation to the role of the bureaucracy) and the practices and procedures from the social construction of organizational actors. The passages in the delegates' reports illustrate that, even considering the level of required standardization in a police organization, even the leaders of grass-roots organizations (police district) are different in any aspects of activity and the organizational culture.

\section{Introdução}

No Brasil, a criminalidade tem atingido índices cada vez mais elevados e o tema tem sido bastante debatido. Entre 1980 e 2000, conforme dados do Instituto Brasileiro de Geografia Estatística (IBGE, 2008), a taxa de mortalidade por homicídios cresceu $130 \%$. Os gastos com segurança pública também merecem destaque, pois representaram, em 2007, 5\% do Produto Interno Bruto (PIB) brasileiro, aproximadamente R\$ 92 bilhões (Terra, 2008). Estes dados ilustram a relevância social e econômica do assunto; porém, em termos acadêmicos de administração, este tema tem recebido pouca atenção, com uma baixa produção científica, conforme indicou a pesquisa exploratória realizada para este estudo. 
Com o aumento da violência e da criminalidade, as pressões da sociedade forçam o surgimento de novos formatos organizacionais ou o aperfeiçoamento das instituições repressoras existentes para que tenham as competências necessárias a fim de minimizar este problema. As organizações policiais, em regra, têm missões semelhantes de preservação do direito e da ordem pública, de prevenção da criminalidade e de assumir o papel de defensores do regime de normas e regras (Fairchild, 1989); porém, as complexas peculiaridades na mensuração de seus resultados poderiam levar a uma indefinição quanto à melhor forma de alcançar seus objetivos, pois a manutenção da ordem pelas polícias deixa marcas profundas em sua interação com os diferentes grupos sociais.

Beato (2001) afirma que as organizações policiais funcionam como no século XIX, mas enfrentam os complexos problemas do século XXI. Não sem razão, em outros países este foco de análise vem passando por diversas discussões, seja por profissionais da área ou por estudiosos de administração. Por outro lado, o que se verifica é que há pouca produção acadêmica sobre a gestão da segurança pública com o enfoque da administração no Brasil. Este é um campo de análise a ser abordado com maior ênfase, não apenas pela sua relevância socioeconômica, mas também pelas contribuições que a análise das organizações pode proporcionar (Cruz e Barbosa, 2002). Segundo aponta Villaça (2003):

Na literatura científica, muito se encontra sobre os conceitos, técnicas, métodos de formulação e implementação de propostas de mudança organizacional. Apesar da quantidade de textos escritos, pouca atenção tem sido dispensada aos esforços empreendidos pelas organizações públicas em programas de melhoria de suas estruturas internas. Dentre elas, as organizações policiais são ainda pouco conhecidas da literatura quando a temática é Gestão Administrativa.

Já os estudos acerca da cultura organizacional também têm grande importância, pois o ambiente atual é de constantes mudanças e as organizações necessitam desenvolver ações estratégicas de flexibilização da cultura empresarial. Assim, considerando a relevância dos dois tópicos, este artigo manteve o foco na avaliação da cultura organizacional de entidades encarregadas da segurança pública. Acredita-se que a análise conjunta sobre esses temas apresenta grande relevância, já que a cultura organizacional é um fator importante para as ações estratégicas de qualquer organização e influencia, consequentemente, seu desempenho. 
Este artigo se propõe, portanto, a complementar o conhecimento dessas entidades, a partir de um foco específico em uma polícia judiciária - a Polícia Civil do estado do Ceará. Com este propósito, acredita-se que será possível apresentar evidências ilustrativas das características organizacionais em termos de cultura e contribuir para uma melhor compreensão desse contexto com as peculiaridades próprias do serviço público, mais especificamente das instituições repressoras ao crime.

Dessa forma, o objetivo deste artigo é analisar a cultura organizacional da Polícia Civil do estado do Ceará, sua forma, suas nuances, as especificidades e as subjetividades, as quais vão além daquilo que é legalmente constituído através de mecanismos como leis, regras e regulamentos.

O artigo está assim distribuído: na primeira parte abordaremos os fundamentos teóricos da pesquisa; em seguida, apresentamos o percurso metodológico que moldou a pesquisa de campo; o próximo item traz os resultados levantados a partir das entrevistas realizadas; ao final, são feitos os comentários finais e recomendações.

\section{Referencial teórico}

\subsection{Fundamentos da cultura organizacional}

O campo da cultura organizacional apresenta grande diversidade, parecendo um grande mosaico, com distintos enfoques, abordagens e mesmo definições. Ainda na década de 1970, Pettigrew (1979) buscou compreender como as culturas organizacionais são criadas, focando a relação simbólica para a formação da cultura organizacional. Para esse autor, o homem é um criador de símbolos, linguagens, crenças, visões, ideologias e mitos, ou seja, um criador e gestor de significados (Pettigrew usou a definição antropológica de símbolos como objetos, atos, relacionamentos ou formação linguística que criam ambiguidade por uma multiplicidade de significados, evocando emoções e impulsionando o homem para a ação).

Martin (1992) afirmou que a cultura poderia ser dividida em três abordagens: integração, diferenciação e fragmentação, que estariam associadas a três tipos de interesse de pesquisa: gerencial, crítico e descritivo. A abordagem de integração está ligada ao referencial gerencialista/funcionalista e, portanto, é de grande utilização. Tal abordagem orienta-se pelo consenso no nível organizacional, onde a cultura é vista como homogênea, excluindo-se qualquer possibilidade de ambiguidade. A perspectiva de diferenciação já supõe 
um consenso no nível de subculturas, ou seja, na organização haveria espaço para várias subculturas que podem conviver em harmonia, independência ou conflito. Isso possibilitaria uma análise sobre dinâmicas de poder, desigualdade e dominação nas organizações. Por fim, a abordagem da fragmentação trabalha com uma visão de falta de consenso pela multiplicidade de interpretações e foca a diversidade cultural e sua consequente ambiguidade.

Entretanto, ainda que tivesse destacado uma divisão, Martin (1992) sugeriu que pesquisadores usassem simultaneamente suas três abordagens sobre a cultura, visto que haveria uma complementaridade e superação das limitações de cada uma delas, se vistas de forma isolada. De acordo com Martin (1992), ao combinarmos as três perspectivas à cultura organizacional, temos uma variedade de insights que cada abordagem isoladamente não oferece, o que permitiria interpretações mais completas sobre a cultura organizacional.

Denison (1996) distinguiu a cultura do que chamamos de clima organizacional. Para ele, a cultura refere-se à profunda estrutura da organização, sendo esta arraigada a valores, crenças e pressupostos que interligam os membros organizacionais, significando estabilidade através da socialização de grupos que convergem no local de trabalho. Essa interação reproduz um mundo simbólico que permite que a cultura tenha estabilidade e certa fragilidade firmada na dependência de um sistema de ação e cognição individual. Já o clima, em contraste, descreve o ambiente organizacional enraizado em um sistema de valor organizacional, mas tende a apresentar esse ambiente em termos relativamente estáveis. Assim, o clima é considerado relativamente temporário, sujeito a um controle de direção e largamente limitado aos aspectos do ambiente social que são conscientemente percebidos pelos membros organizacionais.

Quanto à definição de cultura organizacional, considerou-se bem completa aquela proposta por Schein (2004:17), para o qual a cultura representa:

Um padrão de pressupostos básicos que um determinado grupo criou, descobriu ou desenvolveu lidando com seus problemas de adaptação externa e integração interna, que funcionaram bem o suficiente para serem considerados válidos e, por isso, serem ensinados aos demais integrantes do grupo como a maneira correta de perceber, pensar e sentir em relação aos problemas.

Já Fleury (1996) considera cultura organizacional como um conjunto de valores expressos em elementos simbólicos e práticas organizacionais, que possuem a capacidade de ordenar, atribuir significações, construir a identidade organizacional. Freitas (2000) reforça essa visão cultural exclusiva de cada 
organização, quando entende a cultura organizacional como um instrumento de poder institucional e ainda como um conjunto de representações imaginárias, construídas e reconstruídas nas relações cotidianas. Tais relações são expressas em termos de valores, normas, significados e interpretações, visando um sentido de unidade e direção, que coloca a organização como uma fonte de identidade e de reconhecimento para seus membros. Freitas (2000) afirma ainda que é através da cultura organizacional que se define e repassa o que é importante, qual a maneira apropriada de pensar e agir em relação aos ambientes internos e externos, o que é uma conduta aceitável, o que é realização profissional e pessoal, quais os símbolos a serem cultuados e perseguidos.

A manifestação da cultura organizacional se dá através de ritos, de mitos, das cerimônias etc., que, para Freitas (2007), são meios pelos quais nos manifestamos culturalmente e, embora a literatura os tenha apresentado ainda na década de 1980, eles permanecem válidos, não havendo assim uma mudança radical em relação ao enfoque dado. Trice e Beyer (1984) conceituaram rito como um conjunto de atividades planejadas, dramáticas e relativamente elaboradas que consolidam várias formas de expressão cultural dentro de um evento, que se dá através de interação social, usualmente para o benefício de uma audiência. $\mathrm{O}$ cerimonial refere-se a um sistema conectado de muitos ritos com uma ocasião ou evento simples.

Nota-se aqui uma distinção de magnitude, pois o rito envolveria um número discreto de formas culturais, enquanto o cerimonial conecta muitos ritos dentro de um evento simples. A importância de rito e de cerimonial para Trice e Beyer (1984) no ponto de vista organizacional é semelhante à posição antropológica de Geertz (1989), na qual rito e cerimônia podem até não ser a principal chave que abre todos os significados da cultura, mas eles são eventos nos quais muito da cultura aparece.

Conforme Fleury e Fischer (2000), existem vários meios para se identificar a cultura de uma organização. Entre eles, merecem destaque:

$\checkmark$ o histórico das organizações - o momento de criação de uma organização e sua inserção no contexto político e econômico da época proporcionam a base necessária para compreensão da natureza da organização, suas metas, seus objetivos;

- os problemas críticos por que passou a organização, tais como crises, expansões, pontos de inflexão, de fracassos ou sucessos, também são formadores de sua história;

v o processo de socialização de novos membros — o momento de socialização é importante para a reprodução do universo simbólico. É através das estra- 
tégias de integração do indivíduo à organização que os valores e o comportamento vão sendo transmitidos e incorporados pelos novos membros;

- as políticas de recursos humanos - elas têm papel importante no processo de construção de identidade da organização por serem as mediadoras da relação entre capital e trabalho. Analisando as políticas explícitas e principalmente as políticas implícitas de recursos humanos de uma organização é possível identificar e interpretar os padrões culturais dessa organização;

- o processo de comunicação - a comunicação é um dos elementos essenciais no processo de criação, transmissão e cristalização do universo simbólico de uma organização. É preciso identificar os meios formais orais (contatos diretos, reuniões) e escritos (jornais, circulares, memorandos).

\subsection{Cultura organizacional no setor público}

A cultura organizacional do setor público, embora espelhe muitos elementos já analisados para a cultura organizacional em geral, possui particularidades que merecem análises específicas.

Drucker (2002) conferiu às organizações públicas um caráter estratégico para o desenvolvimento econômico, social, cultural e político de um povo. Assim, com as mudanças ocorrendo em todas as esferas da sociedade e com a importância dos serviços prestados por organizações públicas sendo cada vez mais reconhecida, muito esforço tem sido empreendido no sentido de melhorar o desempenho dessas organizações. Dussault (1992:13) afirma que:

As organizações de serviços públicos dependem em maior grau do que as demais do ambiente sociopolítico: seu quadro de funcionamento é regulado externamente à organização. As organizações públicas podem ter autonomia na direção dos seus negócios, mas, inicialmente, seu mandato vem do governo, seus objetivos são fixados por uma autoridade externa.

Dussault (1992) ressalta ainda que os órgãos de serviços públicos estão sujeitos à interferência do poder político, pois são administrados pelo poder público: eles têm a missão de prestar serviços à sociedade, e esta prestação de serviços está, normalmente, em desacordo com a limitação dos recursos recebidos por eles; quando não há disponibilidade de recursos, eles tendem 
a depender da decisão política e das oscilações da capacidade econômica do Estado, abrindo caminho para decisões politicamente guiadas.

Segundo Pires e Macedo (2006), a distinção entre organização pública e privada está na descontinuidade administrativa, resultando em características como:

- projetos de curto prazo - cada governo só privilegia projetos que possa concluir em seu mandato, para ter retorno político;

v duplicação de projetos - cada novo governo inicia novos projetos, muitas vezes quase idênticos, reivindicando a autoria para si;

v conflitos de objetivos - conflito entre os objetivos do corpo permanente e do não permanente pode gerar pouco empenho em relação aos procedimentos que vão contra interesses corporativos, ciência de que a chefia logo será substituída;

v administração amadora - administração feita por indivíduos com pouco conhecimento da organização e, muitas vezes, sem o preparo técnico necessário, devido ao predomínio de critérios políticos em detrimento da capacidade técnica ou administrativa dos nomeados.

Em uma perspectiva brasileira, segundo Kant-de-Lima (1995), a administração pública estrutura-se fortemente baseada em um modelo de gestão que sobrevaloriza o caráter jurídico da ação pública, mas socialmente pauta-se no sistema de privilégios personalistas da corte lusitana. Essa situação reforça o espírito patrimonialista que marcaria o Estado brasileiro até as tentativas de implementação de uma burocracia pública no Brasil a partir de meados do século XX. O modelo burocrático implantado avançou em termos de sua racionalidade, mas manteve traços da ética patrimonialista, além de ter sido limitado pela política em sua implementação, o que gerou uma modernização incompleta, ressabiada, descolada e ressentida da política.

Já para Martins (1996) a origem do sistema de justiça a partir da colonização portuguesa é uma fonte importante para o entendimento do funcionamento do modelo hoje vigente. A ética lusitana, surgida a partir da expansão ultramarina, preconizava a possibilidade do enriquecimento a partir das colônias, além da necessidade de centralização e concentração do poder real. A formação do Estado brasileiro segue as mesmas premissas de centralização, regulações embaralhadas, além da forte influência da Igreja do Estado português. A hierarquia era complexa e confusa, composta de muitos auxiliares, valendo-se da proximidade com a Coroa para o exercício do poder. 
Os estudos da Escola Nacional de Administração Pública (Enap), apresentados em Zago e colaboradores (2004), mostram que as principais características dessas organizações no Brasil são clientelismo, protecionismo, patrimonialismo, paternalismo, personalismo, individualismo, legalismo, impunidade, sigilismo e descontinuísmo. Outro dado obtido nesse estudo é o perfil da maioria das instituições públicas brasileiras, cuja configuração mostra o predomínio do apadrinhamento político, as relações de favorecimento pessoal e os privilégios que contornam as normas formalmente instituídas.

\subsection{Organizações públicas policiais brasileiras}

O sistema de segurança pública no Brasil é, atualmente, composto por diversos entes: polícia federal, polícia rodoviária federal e guarda nacional, todas componentes da estrutura da União; polícia civil e polícia militar, ambas em nível estadual; e guarda municipal, facultada aos municípios que a queiram compor. As práticas das organizações policiais no Brasil devem ser entendidas como reflexo das ideologias política, legal e judicial, assim como o exercício do poder e a administração da justiça na sociedade brasileira (Kant-de-Lima, 1995). O estudo sobre uma organização pública policial realizado por Villaça (2003) mostrou uma cultura organizacional complexa, devido à heterogeneidade dos subgrupos que a compõem.

Cruz e Barbosa (2002) destacam que as práticas policiais e do sistema judicial brasileiro no século XIX reforçaram as características de uma categorização elitista e excludente, baseadas em uma suposta falta de discernimento da população brasileira, em termos de sua participação na definição das práticas políticas e sociais no país. Segundo Bretas (1997), nos primeiros anos após a proclamação da República até início do século XX, a organização policial buscou afirmar seu monopólio do exercício repressivo na disputa com outras instituições armadas, ou dotadas de poderes coercitivos. No Rio de Janeiro, destacavam-se os policiais civis, a Brigada Policial da Capital Federal, os militares da Marinha e do Exército, guardas nacionais e noturnos, com registros de diversos conflitos entre seus membros. Além dessas interfaces e suas atribuições de manutenção da ordem pública, as atividades da polícia tinham como destino o Poder Judiciário, outro foco de disputa, com ambas as instituições imputando à outra o fracasso de suas ações (Bretas, 1997).

Bretas (1997) ressalta ainda que as atribuições dos policiais variavam das mais simples, como a fiscalização do trânsito, até as mais obscuras atividades de polícia política. O trabalho da polícia envolvia um conjunto de ações 
de ameaça à ordem pública, principalmente nas grandes manifestações populares, como feiras, festas e greves, além de eventos de menores dimensões, geralmente de cunho individual, próprio do trabalho policial, como assassinatos, seduções e dívidas não pagas. As principais infrações referiam-se a ofensas físicas, furtos e roubos, jogo e vadiagem. Mas o tratamento ao cidadão variava de acordo com classe social, nacionalidade, raça e gênero, valendo para a classificação a subjetividade do policial.

Conforme Cruz e Barbosa (2002), a transição política originada na década de 1920, aliada aos conflitos entre as organizações ligadas à segurança, provocou a criação por diversos governos estaduais de guardas civis, corporações uniformizadas, sem caráter militar, que seriam extintas em 1969, com sua anexação às forças militares estaduais. Para uma ideia da dimensão dessas instituições, a Guarda Civil de São Paulo criada em 1924 contava com 15 mil integrantes em 1964.

Na Era Vargas destacou-se a ação da polícia política dentro da polícia investigativa. Com a redemocratização do país não se verificaram maiores mudanças no aparato policial. Isto ocorre com o golpe militar de 1964, quando ações de caráter repressivo com viés político ganharam vulto e culminaram com a edição do Decreto-lei oㅜ 1.072, de 30 de dezembro de 1969, que extinguia as corporações policiais civis locais e as transformava de guardas civis em polícias militares, subordinadas às Forças Armadas. Nesse período reforçamse as características de arbítrio e violência das organizações policiais.

Cruz e Barbosa (2002) apontam a dificuldade de controle dessas organizações que, mesmo após a transição democrática em meados da década de 1980, não se modificaram, pois as ações contra os crimes comuns seguem as linhas traçadas antes e durante o período de exceção, enriquecidas pelas arbitrariedades empregadas pela militarização do policiamento preventivo. As denúncias de violação dos direitos humanos e as práticas discriminatórias da polícia constatam esta situação (Cruz e Barbosa, 2002).

Zaverucha (2000) discute a transição democrática, indicando seus pontos de fragilidade a partir da Constituição de 1988, que marca um continuísmo das elites civil e militar no aparelho do Estado. Apesar de tirar a polícia das Forças Armadas, a Carta Magna manteve a divisão entre Polícia Militar e Polícia Civil, segundo Zaverucha (2000), uma indutora de conflitos entre as instituições. Além disso, dificulta a prevenção e repressão da criminalidade, atividades de caráter civil, ao determinar que as atividades de polícia administrativa, que realiza a prevenção e repressão imediata, seja incumbência das polícias militares, e que a polícia judiciária, que apura as infrações pessoais 
e auxilia o Poder Judiciário, reprimindo após a ocorrência da infração penal, seja responsabilidade da Polícia Civil.

Zaverucha (2000) destaca a urgente necessidade de se reformular o modelo policial brasileiro, com uma organização policial de caráter civil que possa executar o ciclo completo de polícia, e esteja mais próxima da comunidade. $\mathrm{O}$ aumento substancial dos índices de criminalidade e eventos como os movimentos grevistas iniciados nas organizações policiais militares em 1997 representam um indicativo da necessidade de mudanças, que passou recentemente pela discussão de sua origem em características organizacionais.

\subsection{Cultura organizacional em órgãos policiais}

Considerando o propósito deste artigo, foi feito um levantamento na literatura sobre análises da cultura organizacional em instituições policiais. Conforme foi possível verificar, os estudos nessa orientação são limitados, porém são bem consistentes alguns dos trabalhos publicados nessa área (Tavares, 1996; Cruz e Barbosa, 2002; Guimarães e Cartaxo, 2002; Saraiva, 2002; Villaça, 2003; Zago et al., 2004; Pires e Macedo, 2006; Santos Filho, 2006).

Para Cruz e Barbosa (2002), as organizações policiais são centradas na autoridade legal, legitimadas pelas regras e regulamentos, que representam normas abstratas e que fixam as atividades e seus limites. $O$ regulamento disciplinar existente nas organizações policiais é um dos fatores instrumentais que as caracteriza como burocracia.

Sapori (apud Cruz e Barbosa, 2002) realizou uma pesquisa nas organizações do sistema de justiça criminal brasileiro, a qual revelou que estas apresentam um arcabouço estrutural próprio, com a especificação de mando e subordinação. Apresentam também características como divisão do trabalho, racionalidade, profissionalismo, rotinização, padrões formais de autoridade, padronização de procedimentos, normas exaustivas e um produto final definido, "a sentença". Sapori afirmou ainda que o sistema de segurança pública caracteriza-se como uma network organizacional, pois identifica um padrão estável nas relações entre os atores que ocupam o sistema através de um conjunto de conexões diretas e indiretas entre eles, revelando seus tipos, vínculos e laços existentes. O poder circula de forma distinta entre os componentes do sistema, dependendo de sua posição estratificada em relação às demais organizações, sendo valorizados a posse de informações e o domínio de recursos escassos.

Para um combate efetivo da violência e da criminalidade, o sistema de justiça criminal, principalmente as organizações policiais, necessita de uma 
reforma que o leve a atuar em consonância com as premissas de uma administração pública voltada para o atendimento ao cidadão, dentro dos parâmetros democráticos e tendo em vista as tendências preconizadas por Bayley (apud Cruz e Barbosa, 2002).

\section{Metodologia}

Diante do entendimento dos autores sobre a insuficiência de trabalhos sobre cultura organizacional em organizações policiais no Brasil, foi realizada uma pesquisa exploratória para contribuir com a consolidação da compreensão do tema no país. A pesquisa é também descritiva porque faz um levantamento e observação das características de um grupo, pesquisando, registrando e analisando o fenômeno.

Burrel e Morgan (1979) defendem que a investigação nas ciências sociais é baseada na inter-relação da ontologia, da natureza humana e da epistemologia, existindo, assim, paradigmas que buscam explicar a teoria social. Partindo de suposições sobre a natureza da sociedade e sobre a natureza da ciência, esses autores propuseram quatro paradigmas mutuamente excludentes dispostos em dois eixos: sociologia funcionalista, sociologia interpretativa, humanismo radical e estruturalismo radical. Esta pesquisa se enquadra na perspectiva da sociologia interpretativista, que procura compreender o mundo a partir da consciência e da subjetividade individual, com a busca de uma visão alternativa ao positivismo e à defesa de uma perspectiva voluntarista do homem. Nessa ótica, o mundo social é visto como um processo emergente criado pelos indivíduos.

Do ponto de vista ontológico, partimos do pressuposto de que a realidade é relativa, específica, construída social e localmente entre os diferentes atores sociais, é derivada de palavras, símbolos e gestos, que são significados atribuídos pelo homem. Assim, a ação humana é baseada em elementos subjetivos, advinda de sua própria experiência, formação, visão de mundo etc., ou seja, vemos a realidade como uma construção social que possui particularidades, construída e moldada a partir de uma visão coletiva de mundo de todos aqueles que dela fazem parte, como é o caso de cada unidade organizacional.

Do ponto de vista epistemológico, esta pesquisa se baseará, reforçamos, no paradigma interpretativista como base de seu desenvolvimento, por entender que a realidade social não pode ser moldada apenas por explicações funcionalistas, em que causas e efeitos ajustam-se através de regras generali- 
záveis. Trabalhamos com a perspectiva de que os resultados aqui discutidos são criados a partir do próprio processo de investigação e relacionados a seus contextos de investigação, historicamente localizados.

No aspecto metodológico, utilizamos uma abordagem qualitativa. Denzin e Lincoln (2005) afirmam que a pesquisa qualitativa está associada a um campo historicamente complexo, que pode significar diferentes coisas em variados momentos. Esse tipo de pesquisa envolve uma aproximação interpretativa do mundo, estudando coisas no ambiente natural, tentando interpretar fenômenos em termos dos significados atribuídos pelas pessoas, conferindo uma variedade de caminhos epistemológicos e metodológicos.

Na pesquisa qualitativa os participantes não são estabelecidos por critérios estatísticos, mas sim por questões de profundidade daquilo que se investiga (Patton, 1990). Para Patton, a validade, significado e insights gerados na pesquisa qualitativa têm mais relação com a riqueza dos casos selecionados e as competências de observação e análise do pesquisador do que com o tamanho da amostra.

O instrumento de coleta de dados foi o roteiro semiestruturado de entrevista. Segundo Gaskell (2002), a entrevista, que serve para mapear e compreender o mundo da vida dos respondentes, é o ponto de entrada para o cientista social introduzir esquemas interpretativos para compreender as narrativas dos atores em termos mais conceituais e abstratos, sendo o objetivo, a compreensão detalhada das crenças, atitudes, valores e motivações, em relação aos comportamentos das pessoas em determinados contextos sociais.

O objeto de análise foi a Polícia Civil do estado do Ceará. Ao todo foram realizadas oito entrevistas, que foram transcritas e analisadas diante dos objetivos da pesquisa. Os respondentes foram: dois delegados de polícia, ambos homens e bacharéis em direito, com oito e 35 anos de instituição, respectivamente; três escrivãs, cargo com exigência de nível médio, sendo uma com três anos, outra com sete anos e a terceira com 20 anos na Polícia Civil; três inspetores, sendo dois homens, um com dois e outro com 23 anos na organização, e uma mulher com dois anos na instituição - estes três últimos ocupantes de um cargo com exigência, até então, de nível médio. A pesquisa de campo foi realizada entre maio e junho de 2008.

\section{Resultados da pesquisa empírica}

A Polícia Civil do estado do Ceará é uma polícia judiciária vinculada à Secretaria de Segurança Pública e Defesa Social (SSPDS) e tem como chefe máximo 
o governador do estado, seguido pelo secretário de estado da SSPDS. Dentro da estrutura da própria Polícia Civil, há o comando exercido pelo delegado superintendente, servidor de carreira da instituição, nomeado pelo chefe do Poder Executivo estadual. Os servidores que fazem parte dos quadros dessa instituição ingressaram, via de regra, por meio de concurso público de provas ou provas e títulos. A estrutura hierárquica da organização, a partir da superintendência, é demonstrada na figura a seguir.

No intuito de alcançar os objetivos propostos, a análise baseou-se nas seguintes categorias: hierarquia e respeito a normas; prestígio da instituição e credibilidade; mudança e resistência à mudança; e burocracia.

Quanto à questão de hierarquia e respeito a normas, um dos principais elementos esperados da cultura policial é a rigidez hierárquica e o respeito à norma. Para Dellasoppa (2002), a polícia não é um corpo transparentemente organizado; pelo contrário, é o âmbito de conflitos entre seus membros, relações de poder, influências, negociações e trade-offs, corrupção e cálculo racional por parte de seus membros.

\section{Figura}

Organograma da Polícia Civil do estado do Ceará

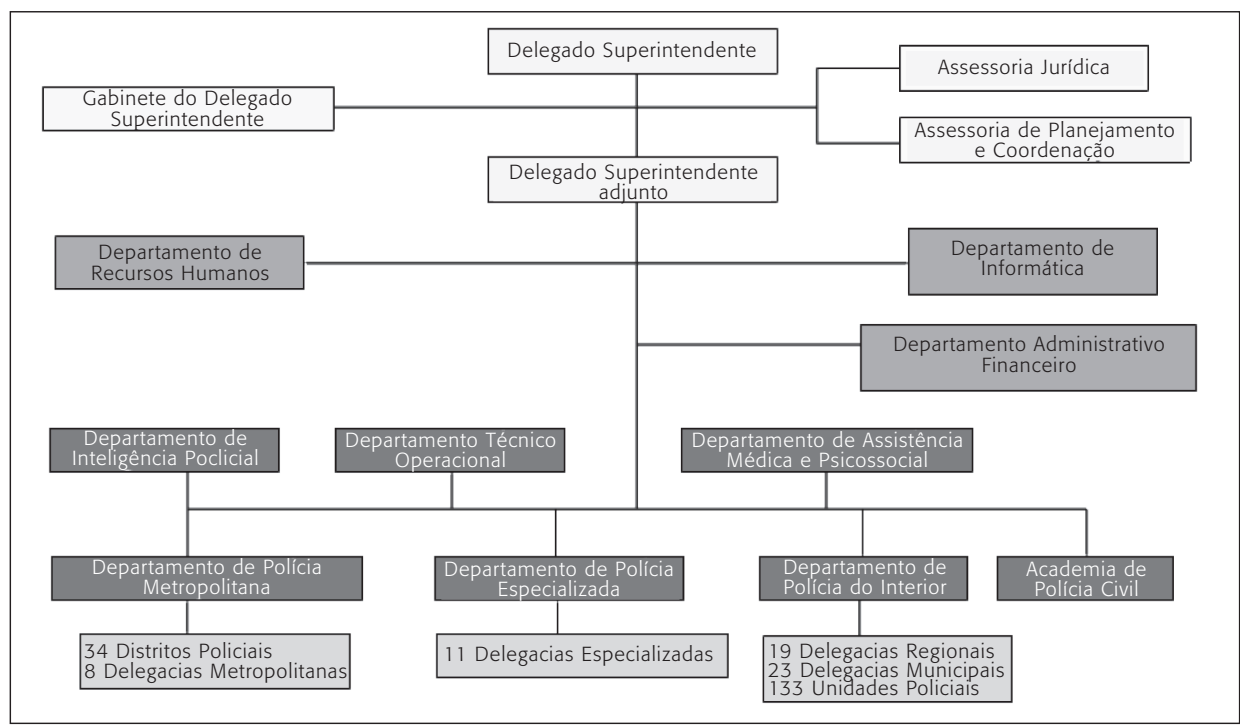

Fonte: Polícia Civil do estado do Ceará (2008).

Um aspecto apontado por todos os entrevistados foi que, independentemente da rigidez, as normas de conduta são necessárias tanto para estabelecer 
um padrão de atendimento ao usuário e de desempenho dos servidores como para a própria condução do grupo. Segundo comenta um delegado com 35 anos na instituição, as normas "são rígidas, mas só com as normas de conduta você é capaz de aglomerar e conduzir o grupo". Uma característica apontada para o cumprimento das normas de conduta é a hierarquia bem definida que a polícia possui. Alguns servidores consideram as normas de conduta rígidas porque realmente devem ser, principalmente por proporcionar um padrão que defina um modelo para ser seguido. Com relação a isso um inspetor com 23 anos na organização afirmou: "Rígidas todas as normas são. [...] Então você tem que segui-la. [...] Sou regido por essas normas e concordo, se eu não concordasse estaria fora do estado".

Porém, alguma ambiguidade está presente nas falas dos respondentes. Uma escrivã com 20 anos de profissão afirmou que o respeito a normas "é para uns e não é para outros. Mas está mudando bem rápido. Os funcionários estão começando a ser punidos".

A relação hierárquica da estrutura policial é rígida e calcada em alinhados manuais de norma e conduta. Dentro desta relação, são muito claros os papéis de superiores e subordinados e são clássicas as visões antagônicas entre os dois lados. Na organização analisada não é diferente e ainda ficam acentuadas pela rigidez na política de procedimentos e comportamentos comuns a este tipo de organização. Tal antagonismo pode ser visto nas palavras de um delegado, com 35 anos de experiência:

Têm acesso fácil, fácil. Dentro dessa conjuntura que eu falei, tem muitos policiais que trabalham aqui que entram aqui a qualquer hora e eu não fico aqui isolado. Até porque você só pode ser um bom chefe se você conhecer seus funcionários. Você necessita conhecer seus funcionários. Se você se enclausura e não recebe seus funcionários, não conhece as fraquezas deles, nem sabe do que ele é capaz você jamais será um bom chefe e jamais terá condições de dominar o grupo. Você só domina o grupo, não é por coação, eu trabalho aqui com 35 pessoas e não é por coação. Eu quero mostrar a eles que eu tenho mais conhecimento que eles, aí eles param, entende? Essa é que é a necessidade, o chefe tem que mostrar que tem um conhecimento mais alargado, mais longe do que os servidores, porque se ele não mostrar e se ele começar a se enclausurar com medo porque tem um é aluno, o outro é não sei o quê, aí os outros vão começar a boatar dizendo que ele se enclausura porque ele não tem papo, não tem poder, não sabe conversar, não sabe determinar, então ele tem que abrir o leque daquilo que é seu. 
E uma subordinada sua, uma escrivã, com três anos de função, afirma:

O acesso em geral não é tão fácil assim e pelo que eu já sondei de colegas que tiveram que procurar não tem esse acesso assim fácil. Porque aquele negócio, acho que é coisa até de cultura, quem está no poder acha que está num degrauzinho a mais e a gente sabe que não é bem assim. Quem está no poder a gente sabe que tem seus privilégios e responsabilidades também. O que é que acontece, tem que ouvir ali o todo para saber o que é que a gente pode melhorar, o que é que está faltando. Eu acho que falta esse canal até de comunicação.

Ou ainda outra subordinada, uma escrivã com sete anos de polícia, afirma: "O diálogo não é tão bom quanto deveria ser, acho que poderia ter um diálogo melhor até para melhorar a estrutura, de estar ouvindo o que é que precisa. Não é ainda o adequado, poderia melhorar mais".

O segundo aspecto destacado nesta pesquisa diz respeito ao prestígio da instituição policial. A maioria dos entrevistados vê a instituição Polícia Civil como sem prestígio junto à sociedade cearense. Isso se deve tanto pela estrutura da própria instituição quanto pela falta de confiança em seus servidores. Quanto a isso, Pinc (2006) concluiu em seu trabalho que a confiança do cidadão na instituição policial é um patamar social difícil de ser alcançado, não apenas porque uma parcela de seus representantes adota comportamento desviante e abusa do poder, mas, principalmente, em razão da peculiaridade do serviço policial, que, mesmo respeitando o aspecto legal, tem grande probabilidade de ser associado a uma experiência negativa, cujo fator tem efeito direto na desconfiança, a qual pode ser generalizada. Essa falta de confiança no trabalho da polícia foi evidenciada por uma escrivã com três anos na Polícia Civil: "A gente tem dificuldades junto à sociedade. As pessoas veem acontecer os crimes, mas quando chega a polícia para notificar ou para cumprir as suas diligências, ninguém viu... ninguém sabe".

Acredita-se também que a falta de prestígio, notada pelos próprios servidores, ajuda a entender a falta de interesse da comunidade científica em publicações nessa área, restringindo-se geralmente apenas àquelas pessoas que trabalham na área. Pode ser que a restituição teórica do prestígio perdido estimule pesquisas empíricas e estudos propositivos de que tanto necessitamos (Soares e Garotinho, 1998).

As pessoas não confiam na polícia por diversos escândalos recentes com envolvimento de policiais em corrupção, em outros variados crimes e em desvios, bem como devido à repressão e sua ineficácia, principalmente em relação à população excluída (Lima, 2003). Um delegado, com oito anos na 
instituição, atribuiu a culpa pela exposição da Polícia Civil apenas na ocasião de escândalo à imprensa:

Hoje em dia, a própria sociedade discrimina muito a polícia, a polícia em geral: militar, civil e federal. Falou o nome polícia já há uma antipatia da sociedade. Isso eu posso até atribuir parte desta culpa à imprensa. Porque a polícia em si, hoje, só é lembrada quando comete algo errado. Quando ela acerta nas ações, faz um trabalho bonito e preventivo, isso é pouco veiculado. É pouco colocado para a sociedade. Não há matérias sobre isso. Agora, quando na Polícia Civil falta um delegado no plantão, comete um desvio de finalidade, ou um inspetor é preso, por exemplo, isso é primeira página do jornal. Alguns setores da imprensa gostam de mostrar a polícia em si só por esse lado, eles não gostam de mostrar a Polícia Civil pelo lado bonito, pelo trabalho bem feito que a polícia faz. Então isso eu vejo como muito grave. Como é que a sociedade vai ter bons olhos para um órgão que só se mostram coisas ruins?

Quanto à questão da credibilidade, e o que está sendo feito para transmitir credibilidade para a sociedade cearense, a retórica dos respondentes foi no sentido tanto da defesa como da deficiência da credibilidade e dos meios que a organização usa para passar esta imagem à sociedade. As palavras de um dos delegados ilustram isto:

A polícia tem se modernizado bastante porque hoje já se encontram fraudes nos concursos, não é? Quer dizer, será que nos outros nunca existiu? É porque hoje está aberto para que o cara fiscalize e encontre a fraude. Talvez não existisse antigamente. Então estas situações representam progresso, até porque se você não progredir, você vai ficar parado, vai ficar estanque no tempo. [...] Você não pode ficar naquela porque você fica ultrapassado, você tem que ir avançando na mesma proporção para poder ter qualidade.

Nas palavras de uma inspetora com dois anos de serviço já encontramos ambiguidades e críticas quanto à possibilidade de transmissão de credibilidade para a sociedade:

Eu acho que credibilidade existe, nunca deixou de existir. É tanto que as pessoas procuram a polícia como primeira opção independente do problema que têm. As pessoas acreditam na Polícia Civil. Agora, acho que a polícia não tem feito nada para manter essa credibilidade. Entretanto, pelo menos aqui a gente faz o que pode, ou seja, nós tentamos dar mais agilidade aos processos, por 
exemplo. Aqui a gente tenta cumprir os prazos, para que as pessoas que foram vítimas tenham a sensação de que foi feita alguma coisa por elas.

Posição próxima para a escrivã com três anos de experiência: "Eu acho que existem algumas iniciativas no sentido de mudar essa percepção da sociedade. Mas iniciativas independentes, de uma pessoa ou outra isolada. Mas no geral não. Não sei informar o porquê de não haver".

$\mathrm{O}$ terceiro aspecto destacado refere-se à mudança e resistência à mudança. Diante dos anseios da sociedade e dos crescentes níveis de violência brasileiros, a mudança nos órgãos policiais parece ser vista como necessária para a população em geral. Tais modificações acabam por gerar tanto apoios como resistências, exacerbando contradições, dependendo da interpretação dos protagonistas. Para o delegado com 35 anos de serviço: "Toda mudança que é feita ela é pensada, estruturada. A intenção da mudança é melhorar, no primeiro momento a intenção da mudança é melhorar. Aí você diz: 'E melhorou?'. Às vezes a mudança não deu certo. Aí você volta e faz outra mudança que pode dar certo".

A opinião de um inspetor com 23 anos de corporação é que "a questão de mudança é um problema. Como é mudança você não está acostumado com aquilo. Então tem uns que gostam, outros não. No meu caso eu acho que qualquer mudança vem no benefício de nós mesmos. Agora tem os que não e os que gostam".

Já para a escrivã com três anos de experiência:

Eu creio que poderiam ser melhor estruturadas na hora de se implementar. Para não ser aquela coisa de se jogar e tem que ser assim e ser. A gente não pode botar a culpa ou só em governo ou em quem quer que seja, mas as pessoas que estão aqui elas têm que compreender também estas mudanças e existe uma resistência.

Mas, para a escrivã com sete anos de serviço há claro conflito entre os protagonistas de "linha de frente" e aqueles de "gabinete", demonstrando a existência de "subculturas" dentro do órgão policial. Para ela:

Existe aquele pessoal que é de órgão, de burocracia e de gabinete. E existe aquele que é de rua, de entrar em contato com a população e às vezes as coisas não se coadunam. Quem sabe o que está acontecendo é quem está trabalhando aqui no dia a dia, é quem está na rua vendo o que é que a população reclama, o que a cidade está necessitando. Não é aquele que fica ali no gabinete sentado for- 
mulando regras. Eu acho que está deixando a desejar neste ponto. Quem sabe o que está acontecendo é quem está lá de frente convivendo com o problema. As mudanças vêm muitas vezes distantes da nossa realidade, da necessidade.

A superação das resistências pode evidenciar uma posição de conflito entre chefia e subordinado e, a partir da relação hierárquica, novos delineamentos surgem. Isso não significa que as tensões estejam superadas. Nas palavras do delegado mais experiente:

Mudança sempre causa ego no paradigma (sic). Ele está acostumado a trabalhar neste horário e na hora que você o põe para trabalhar em outro horário ele já estranha e para adaptação você vai ter que ter o domínio... Você que está chefiando a situação é que tem que ter domínio, pulso e poder de falácia para mostrar que a nova situação é melhor do que a outra.

Para o delegado com menor tempo de serviço, os choques entre superiores e subordinados também ficam evidenciados e acabam por influenciar na própria imagem e ação da Polícia Civil, segundo ele:

A gente como entidade tem uns representantes que são os sindicatos. Os sindicatos cumprem a função deles de batalhar. Há choques de ideias e de interesses, não só na Polícia Civil, mas em qualquer outra instituição. Há sempre aquele choque de interesses entre os comandantes e os comandados. Geralmente, os comandantes pensam no próprio nariz e os comandados pensam como um grupo. Então, eu vejo isso como um fator negativo e trazendo para a Polícia Civil, eu vejo que isso está terminando na Polícia.

Mas a resistência à mudança não é uma regra que impeça que alguns a vejam como necessária e mesmo positiva, como é o caso de uma escrivã com três anos na função:

O desafio maior que eu vejo está na cabeça das próprias pessoas de mudar a sua visão. De não ser só aquela coisa burocrata como falei, está só ali sentada. Procure ver e estar em contato. A gente não vê chegar aqui uma comissão para perguntar como está, como funciona. Acontece, mas é muito raro. Tudo que é novo causa sim da pessoa se fechar, de não ser bem-vinda. Isso é até normal. Não só por parte das pessoas mais antigas, mas também dos nossos dirigentes que têm a visão estreita das coisas. 
O quarto aspecto destacado nas entrevistas foi a questão da burocracia, esta que é uma das características mais populares da estrutura dos governos. Sua associação à lentidão, a excesso de papel, é notória no âmbito da sociedade, no que se refere ao setor público. No âmbito da Polícia Civil cearense, conforme os respondentes, ela é vista como algo negativo no sentido de dificultar o serviço, como vemos nas palavras do delegado de 35 anos de serviço:

A burocracia atrapalha bastante a qualidade do serviço. Se precisa modificar, diminuir esta burocracia, até porque este aqui é um cargo que você tem que ser uma pessoa rígida para poder exercer. Estas burocracias já são exatamente para que você não saia do campo legal do local. Você é fiscalizado, você é vigiado para ver se você se mantém dentro daquele campo. Vai haver uma correção para aquela pessoa que não está cumprindo. E eu acredito que se desburocratizasse mais e se a coisa for mais séria a violência diminui bastante. O problema é a burocracia que atrapalha.

Ou da escrivã, de três anos como policial:

Sem dúvida a burocracia atrapalha muito. Ela emperra muito a máquina administrativa. Emperra muito os nossos serviços de uma forma geral. Embora se adotem certas mudanças, eu acho que não estão acompanhando a evolução das coisas. Nós estamos vivendo uma época diferente, de internet, de velocidade. Nós ficamos impressionados com o nosso instituto de criminalística. A gente fica assim pasmado, porque certas coisas não dão resultado porque dependem de provas técnicas. Então tem que haver a reciclagem dos servidores, o pessoal sempre fazendo cursos, a compra de equipamentos modernos. A gente não vê isso. E não é só em nível de estado, é geral.

Mas há posições distintas para este mesmo fenômeno no órgão investigado, mais uma vez demonstrando ambiguidades e contradições no universo investigado. Segundo a percepção do delegado com oito anos de trabalho:

A Polícia Civil em termos de burocracia não tem burocracia. A burocracia você vê mais na esfera do Poder Judiciário. Naquele negócio para conseguir certidão e tudo mais. Hoje em dia eu não vejo burocracia na Polícia Civil porque a pessoa quer um boletim de ocorrência ela vem e faz, se ela quer um inquérito policial ele é instaurado. Agora, se este demora isso não é problema de burocracia, mas sim problema de estrutura - é mexer com a estrutura. Burocracia é, por exemplo, se eu tiver que fazer um BO eu vou ter que ir a determinado canto, 
passar por determinada pessoa... Isso sim é uma burocracia. Agora, no sentido de estrutura, de demora, é questão de material humano deficiente. Então, isso aí leva a uma demora, por exemplo, um inquérito que era para estar pronto em 30 dias fica em 90 dias, é isso. Isso para mim não é burocracia.

Uma percepção convergente é vista em um inspetor com 23 anos de serviço:

\begin{abstract}
A burocracia existe em todo lugar. No caso da polícia, a gente como tem que investigar, ou seja, é um negócio mais controlado... A gente tem... Agora as pessoas acham que é dificuldade. Não há dificuldade, porque nós temos que partir do princípio de que todo mundo é inocente perante a lei, ou seja, você não pode culpar. Tem uma demora; tem um certo padrão para a gente poder realizar a função.
\end{abstract}

\title{
5. Comentários e considerações finais
}

Os discursos são elementos importantes para compreendermos as nuances que envolvem o universo organizacional. Fiorin (1993) afirma que "discurso são as combinações de elementos linguísticos (frases ou conjuntos constituídos de muitas frases), usadas pelos falantes com o propósito de exprimir seus pensamentos, de falar do mundo exterior ou de seu mundo interior, agir sobre o mundo". Diante da construção social da realidade, os discursos precisam ser interpretados com a luz de uma perspectiva espaço-temporal, onde o discurso é, ao mesmo tempo, produto e produtor da construção social.

Os resultados do estudo de campo são indicativos de alguns aspectos interessantes sobre os tópicos de cultura definidos para análise. Assim, para o tópico referente à hierarquia e às regras, houve certa convergência na opinião de as regras serem necessárias à atividade policial, porém as posições oscilam quanto à percepção de acessibilidade e interação entre os líderes (delegados) e os liderados. Quanto à questão do prestígio institucional, as posições também variaram moderadamente, destacando-se o papel moderador que os mecanismos de imprensa têm em relação à imagem da polícia diante da sociedade em geral (este aspecto é esperado, quando se considera a grande diversidade de programas policiais em televisão e rádio e a grande audiência que estes possuem).

Em geral, a fala dos respondentes indica, como foi possível verificar nas passagens relatadas, que prevalecem, na instituição analisada, posições frag- 
mentadas, ambíguas, que podem surgir a partir das tensões entre estruturas mentais pré-constituídas e práticas e processos oriundos da construção social dos atores organizacionais. As passagens dos relatos dos delegados ilustram que, mesmo considerando o nível de padronização exigido em uma organização policial, até mesmo os líderes das organizações de base são divergentes em diversos aspectos da atividade e da cultura organizacional.

Tensões apareceram também entre aqueles que veem a necessidade de mudança ocorrer de forma mais célere e entre aqueles que coadunam com uma visão de estabilidade. Tais conflitos advêm das diferentes percepções e de aceitar que as práticas sociais sejam mais, ou menos, duráveis, em um jogo de poder para definir as práticas institucionalizadas que são mais adequadas à visão dos subgrupos sociais.

$\mathrm{O}$ aspecto relacionado à mudança fez convergir a percepção dos entrevistados, no entendimento sobre a necessidade e a resistência à mudança. Verificou-se, assim, que no contexto de análise pesquisado não há variações em relação às organizações em geral. O quarto aspecto, associado à visão sobre a burocracia e diretamente relacionado ao primeiro aspecto analisado, ilustrou bem aspectos referentes ao entendimento, primeiramente, do que seja burocracia, e, em seguida, do papel que esta tem na determinação do trabalho. Assim, ficou bem claro que parte dos entrevistados entende a burocracia como um conjunto de regras organizacionais sem racionalidade; esses naturalmente afirmam que a burocracia dificulta o trabalho policial. Por outro lado, é bem ilustrativa das divergências de opinião a avaliação do delegado que informa que o problema não seria em si a burocracia, mas a própria estrutura de trabalho disponível.

Como limitação deste estudo, nos apoiamos em Gaskell (2002), que apresenta três limitações das entrevistas: o entrevistador se apoia na informação do entrevistado, podendo não compreender completamente a linguagem local; o entrevistador pode omitir detalhes importantes, seja porque fica difícil de ser dito com palavras ou porque possa lhe parecer algo dado, aceito sem discussão. Por fim, o entrevistado pode ver situações através de "lentes distorcidas" e fornecer uma versão que seja enganadora. Nesse sentido, tais limitações devem ser vistas quando da análise dos resultados apresentados, especialmente considerando que as entrevistas foram limitadas ao estado do Ceará e a oito pessoas. Nesses termos, acredita-se que outros estudos semelhantes em outros órgãos policiais e em outros estados poderiam contribuir para uma melhor compreensão do tema proposto neste artigo.

Ainda quanto a proposições de trabalhos futuros, indicamos novas pesquisas exploratórias, com distintas perspectivas, com o uso de triangulação 
de métodos de investigação que proporcionem mais robustez ao campo. Isso inclui pesquisas com instituições semelhantes em outros estados brasileiros, bem como no nível federal.

\section{Referências}

BAYLEY, D.H. Padrões de policiamento. São Paulo: Edusp, 2001. Apud CRUZ, M.V.G.; BARBOSA, Allan C.Q. Uma abordagem organizacional na segurança pública: notas para discussão. In: ENCONTRO NACIONAL DE ESTUDOS ORGANIZACIONAIS, II, 2002, Recife. Anais... Recife: Eneo, 2002.

BEATO, C. Reinventando a polícia: a implementação de um programa de policiamento comunitário. Belo Horizonte: Crisp/UFMG, 2001.

BRASIL. Decreto-Lei no 1.072/69, de 30 de dezembro de 1969. Dá nova redação ao art. 3oㅡ. letra A, do Decreto-Lei no 667, de 2 de julho de 1969, e dá outras providências. Diário Oficial da República Federativa do Brasil, 30 dez. 1969.

BRETAS, M.L. A guerra das ruas: povo e polícia na cidade do Rio de Janeiro. Rio de Janeiro: Arquivo Nacional, 1997.

BURRELL, G.; MORGAN, G. Sociological paradigms and organizational analysis. London: Heinemann Educational Books, 1979.

CRUZ, M.V.G.; BARBOSA, A.C.Q. Uma abordagem organizacional na segurança pública: notas para discussão. In: ENCONTRO DE ESTUDOS ORGANIZACIONAIS, II, 2002, Recife. Anais... Recife: Anpad, 2002.

DELLASOPPA, E.E. Estratégias e racionalidade na Polícia Civil do estado do Rio de Janeiro. In: LEÓN, R.B. (Org.). Violencia, sociedad y justicia en América Latina. Buenos Aires: Clacso/Asdi, 2002.

DENISON, D.R. What is the difference between organizational culture and organizational climate? A native's point of view on a decade of paradigm wars. Academy of Management Review, v. 21, n. 3, p. 619-654, 1996.

DENZIN, N.K.; LINCOLN, Y.S. Introduction: the discipline and practice of qualitative research. In: DENZIN, N.K.; LINCOLN, Y.S. (Ed.). Handbook of qualitative research. 3. ed. Thousand Oaks: Sage, 2005. p. 1-32.

DRUCKER, P. Introdução à administração. São Paulo: Pioneira/Thomson Learning, 2002.

DUSSAULT, G. A gestão dos serviços públicos de saúde. Revista de Administração Pública, v. 26, p. 8-19, 1992. 
FAIRCHILD, E.S. National culture and police organization in Germany and United States. Public Administration Review, p. 454-462. Sept./Oct. 1989.

FIORIN, J.L. Linguagem e ideologia. São Paulo: Ática, 1993.

FLEURY, M.T.L. Cultura e poder nas organizações. São Paulo: Atlas, 1996.

FLEURY, M.T.L.; FISCHER, R.M. Cultura e poder nas organizações. São Paulo: Atlas, 2000.

FREITAS, M.E. A questão do imaginário e a fronteira entre a cultura organizacional e a psicanálise. In: PRESTES MOTTA, F.C.; FREITAS, M.E. (Org.) Vida psíquica e organização. Rio de Janeiro: FGV, 2000.

FREITAS, M.E. Cultura organizacional: evolução e crítica. São Paulo: Thomson Learning, 2007.

GASKELL, G. Entrevistas individuais e grupais. In: BAUER, M.W.; GASKELL, G. (Org.) Pesquisa qualitativa com texto, imagem e som: um manual prático. Petrópolis: Vozes, 2002. p. 64-89.

GEERTZ, C. A interpretação das culturas. Rio de Janeiro: LTC Editora, 1989.

GUIMARÃES, T.A.; CARTAXO, M.A. Aprendizagem e cultura nas organizações: um estudo em uma organização militar. In: ENCONTRO NACIONAL DE ESTUDOS ORGANIZACIONAIS, II, 2002, Recife. Anais... Rio de Janeiro: Anpad, 2002. Versão eletrônica. p. 1-15.

IBGE. Síntese de indicadores sociais: taxa de homicídios mais que dobra em 20 anos. Disponível em: <www.ibge.com.br/home/presidencia/noticias/noticia_visualiza. php?id_noticia=132\&id_pagina=1>. Acesso em: 29 jun. 2008.

KANT-DE-LIMA, R. A polícia da cidade do Rio de Janeiro: seus dilemas e paradoxos. Rio de Janeiro: Forense, 1995.

LIMA, M.A. Confiança na polícia. Dissertação (mestrado) — Escola de Governo, Fundação João Pinheiro, Belo Horizonte, 2003.

MARTIN, J. Culture in organizations: three perspectives. New York: Oxford University Press, 1992.

MARTINS, H.F. A ética do patrimonialismo e a modernização da administração pública brasileira. In: MOTTA, Fernandes Prestes (Org.). Cultura organizacional e cotidiano nas organizações brasileiras. São Paulo: Atlas, 1996.

PATTON, M.Q. Qualitative evaluation and research methods. 2. ed. Newbury Park, CA: Sage, 1990.

PETTIGREW, A.M. On studying organizational cultures. Administrative Science Quarterly, v. 24, p. 570-581, Dec. 1979. 
PINC, T.M. Confiança na polícia: um desafio na implementação de políticas públicas. In: SIMPÓSIO DOS PÓS-GRADUANDOS EM CIÊNCIA POLÍTICA, IV. Anais... São Paulo: 2006.

PIRES, J.C.S.; MACEDO, K.B. Cultura organizacional em organizações públicas no Brasil. Revista Brasileira de Administração Pública, v. 40, n. 1, p. 81-105, 2006.

POLÍCIA CIVIL DO ESTADO DO CEARÁ. Disponível em: <www.policiacivil.ce.gov. br/>. Acesso em: 29 jun. 2008.

SANTOS FILHO, N.G. A integração dos órgãos policiais no estado da Bahia: possibilidades e desafios sob um olhar institucionalista. In: ENCONTRO NACIONAL DA ANPAD, XXX, Salvador. Anais... Rio de Janeiro: Anpad, 2006.

SAPORI, L. A administração da justiça criminal numa área metropolitana. Revista Brasileira de Ciências Sociais, São Paulo, ano 10, n. 29, p. 143-157, out. 1995.

SARAIVA, L.A.S. Cultura organizacional em ambiente burocrático. Revista de Administração Contemporânea - RAC, v. 6, n. 1, p. 187-207, 2002.

SCHEIN, E.H. Organizational culture and leadership. 3. ed. San Francisco: JosseyBass, 2004.

SOARES, L.E.B.M.; GAROTINHO, A. Violência e criminalidade no estado do Rio de Janeiro. Rio de Janeiro: Hama, 1998.

TAVARES, F.P. A cultura organizacional como um instrumento de poder. Caderno de Pesquisas em Administração da USP, v. 1, n. 3, p. 67-77, 1996.

TERRA. Ações comunitárias: Brasil gasta R $\$ 2$ bilhões com segurança. Disponível em: < http://invertia.terra.com.br>. Acesso em: 1o jul. 2008.

TRICE, H.M.; BEYER, J.M. Studying organizational cultures through rites and ceremonials. Academy of Management Review, v. 9, n. 4, p. 653-669, 1984.

VILLAÇA, N.A.G. Organizações policiais e a questão da cultura organizacional e possíveis mudanças: análise preliminar. Revista Gerenciais, São Paulo, v. 2, p. 8591, set. 2003.

ZAGO, C.C. et al. A cultura organizacional em uma organização pública: aspectos norteadores para o seu gerenciamento. In: ENCONTRO DE ADMINISTRAÇÃO PÚBLICA E GOVERNANÇA. Anais... Rio de Janeiro, 2004.

ZAVERUCHA, J. Frágil democracia. Rio de Janeiro: Civilização Brasileira, 2000. 
